\title{
Esperanza de estrellas
}

\section{Hope Stars}

\section{Esperança de Estrelas}

\author{
Carmen Martínez Coello \\ Relato finalista X Edición Premio Vida y Salud de Relatos (modalidad profesionales de salud).
}

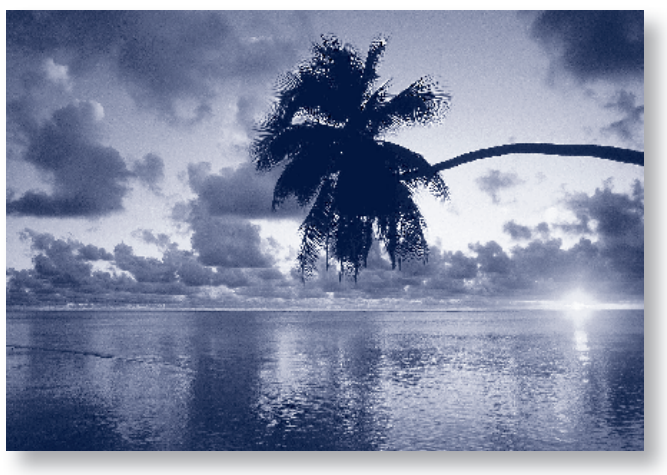

A menudo acude a mi memoria la vida de Juana. Son retazos sueltos, algo que ocurre que me lleva a ella.

Voy a buscar en mi memoria esos recuerdos para atraparlos y guardarlos en el papel. Siempre hago lo mismo cuando no quiero perderlos.

Los recuerdo, los atrapo, los guardo escribiendo y de paso os los cuento...

Cuando la conocí y me detalló su historia increíble, Juana ya había despertado de la pesadilla que había padecido durante años, como quien sufre una adicción, al tabaco, al alcohol ó a cualquier droga. Igual que cuando se lucha contra una enfermedad incurable. Había solo una pareja, en una mesa distante, en el otro extremo de la terraza. Teníamos toda la tarde por delante. Juana pidió una limonada, yo un té al que mitigué su fuego con un cubito de hielo. Todo estaba en calma. Ella me hablaba y respiraba hondo, liberada.

Empezó a contarme su historia despacio. $\mathrm{Su}$ hablar y su gesto, me sugirió imaginarla encajando segura y pausada las piezas de un gran rompecabezas. Durante mucho tiempo, por lo menos cuatro años, vivió una forma de vida contra la que luchaba cada día, pero que al mismo tiempo le atraía como un gran imán.

Ahora veía con claridad. Se recordaba intentando vanamente adaptar a su vida burbujas flotantes de tiempo que venían a su vida y se iban. Tan efímeras, que a veces en la soledad de aquellas noches tan oscuras, llego a dudar si existían.

Juana se enamoró. Vivió una historia de amor verdadero, de esas que nos cuentan en los libros. Conoció ese amor que hace que el mundo gire, pero había un gran problema. Era una historia de amor donde solo amaba ella.

El gran amor de Juana era un pobre diablo, que ya bastante tenía con ser diablo pero pretendió engañarla con un falso amor de verdad. Y que, además de diablo resultó ser un Don Juan.

Su mirada se veló como un cristal empapado de agua.

Recordó aquel presentimiento, como le avisó su intuición, más en su corazón que en su mente. Y como, sin embargo, miró para otro lado.

A partir de entonces, empezó a sentir el daño que sufren los que están atrapados en las redes de una adicción. Saben y reconocen lo que les hace daño, pero siguen, creen que lo pueden dejar cuando quieran, en el momento que decidan hacerlo. Lo que pasa es que cuan- 
do lo intentan, se dan cuenta que no es así, que resulta que no pueden.

Cada día que pasaba, Juana veía como esos momentos maravillosos y aislados que le hacían vivir y le insuflaban aire para respirar el resto del tiempo, se convertían en una trampa mortal. Cuando pasaban, la realidad era una caída libre al abismo más oscuro de sus pesares y contradicciones. La grafica de su vida era como los dientes de una sierra, definidos y cortantes.

El efecto inmediato, cada día era más devastador. Lejos de calmarla le desarrollaba más la dependencia y la angustia. Pensaba que, como con el tabaco, tarde o temprano llega un día que seguro que vas a dejar de fumar. Es el día que sufres un infarto. Pero con eso otro, el corazón se iba muriendo y se llevaba la ilusión y la esperanza. Además percibía claramente como cada día la derrota iba ganando terreno en su vida.

Juana se rebelaba, pero no había nada que hacer, me decía. Era lo que había. El diablo se alimentaba hasta de sus cenizas.

Me dijo, que hubo un de tiempo en que llego a aceptar que el resto de su vida la viviría así. Sería como existir sin vivir. Permaneciendo en un desasosiego constante después de saber lo que es la vida plena, la paz y la calma. Después de sentir el estado de bienestar ideal de las personas y de las cosas, de descubrir por si misma y sentir la fuerza que hace que salga el sol cada día.

Se recordaba siempre triste, cada día que pasaba, un poco más. Solo respiraba. Caminaba por un callejón sin salida, a cada paso más cansada, sin esperanza, sin fuerzas, en la soledad mas profunda. Sentía al contarlo el daño que sufrió en aquel tiempo, como le mordía por dentro. Hasta que, por fin, escuchó lo que resonaba todo el tiempo en su cabeza. Que no podría aguantar mucho más en ese estado, se acabaría muriendo.

Y todavía ahora, me dijo, no puede acordarse bien como fue, pero sucedió. Fue como un renacimiento, como volver a nacer. Poco a poco empezó a recordar cómo era antes de que esa sombra entrara en su vida oscureciéndolo todo. Recordó su fuerza, su optimismo, su sonrisa, su complicidad con ella misma ante el espejo, y empezó a echarse de menos. Recordó sus ilusiones y sus sueños...

Sintió como si le hubiesen robado. Se paró a pensar y se dio cuenta que eso no era del todo cierto, había sido ella quien lo había regalado todo. Había metido su vida entera con su risa, su salud, sus ilusiones, su pasado y su presente, en un sobre cerrado, y lo había echado a un buzón de correos, sin destinatario.

Juana me dijo que fue entonces cuando decidió recuperarlo todo y se vio a si misma, buscándose desesperadamente en una gran oficina de objetos perdidos. Se sintió llena de fuerza y comenzó a buscar sin parar.

Pasaron muchos días llenos de esa mezcla de incertidumbre absoluta y de mucho tiempo de soledad acumulada, pensando que nada iba a encontrar. A veces flaqueaba, pero aprendió a ser práctica. Dedujo que, intentarlo iba a ser igual de duro que no hacerlo, y decidió buscar.

Dudó muchas veces si lo conseguiría, pero la posibilidad de encontrar una salida, por pequeña que fuese, la hacía seguir. Aunque solo fuera una rendija por donde entrase algo de claridad en aquella habitación tan vacía, en aquellos días tan oscuros.

Lo intentó una y otra vez, muchas veces. El simple hecho de intentarlo le daba mas fuerza. Además lo que si veía claro y nítido, era como el pobre diablo caía por un barranco y descendía a los infiernos, hasta que desapareció para siempre. 


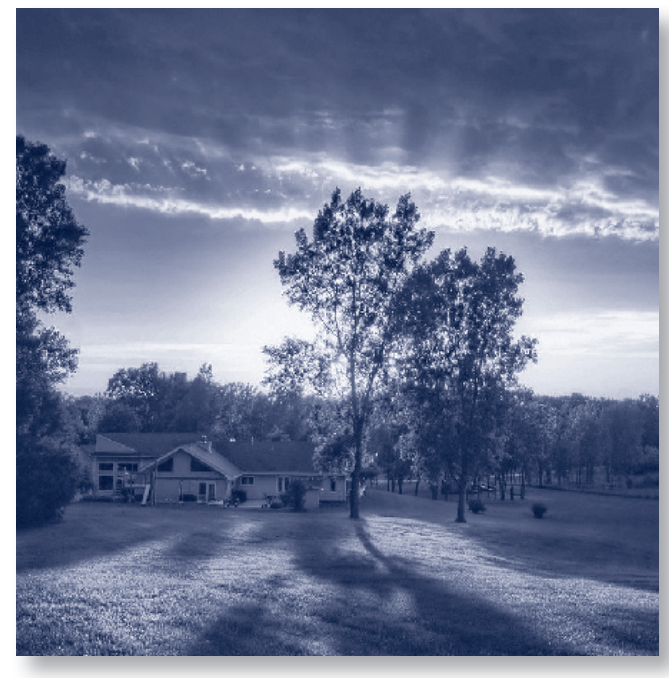

Me contó que hubo día, que no lo recuerda diferente a los demás que habían pasado, pero sí que a partir de entonces fue sintiéndose mejor.

Cerraba los ojos, se miraba por dentro y se sentía a gusto buscando. No podía creerlo pero un día vio como se encendía una luz. Entonces empezó a revolver ahí, a rebuscar sin parar hasta que por fin encontró...

Poco a poco, se acordó de recordar, y sintió como uno a uno, volvían a su mente aquellos momentos de la infancia que formaron su vida, los que habían echado cimientos en su manera de ser.

Se dio cuenta que el secreto, que la llave que tanto buscaba, esa que abría la puerta para salir, la tenía ella...

¡Pero como no se había dado cuenta!

No sabía como, pero volvía a estar allí después de tanto tiempo. Estaba en la casa de su niñez, en el campo, jugando con su pequeña pelota de colores, contando los botes contra la pared..., hasta diez con las manos juntas, luego dando una palmada en la espalda, luego con los nudillos y a sí..., sin fin.

Estaba en su habitación, cuando era una niña. Recordó tardes enteras haciendo su pri- mera librería, juntando y pegando cajas de zapatos vacías. Allí coloco sus primeros libros. Peter Pan, fue el primero. Después una colección de cuentos, luego Agatha Christie y sus intrigas, también los consabidos diccionarios donde la obligaban a buscar cada vez que preguntaba...Era como un gran remiendo que a veces se tambaleaba, pero Juana la miraba fascinada. Su mayor ilusión era verla llena.

Se veía con el mandilón de rayas del uniforme y sus bolsillos manchados de tinta lavada, en los interminables días de colegio. Recordó aquellas mañanas heladoras de invierno calentando la ropa, casi mojada, en la estufa o calentando los zapatos en el horno de la cocina. Era un viaje en el tiempo.

Sintió y revivió con todos los sentidos cada recuerdo.

Sentada bajo las parras contemplaba aquellas cenas de verano en el jardín, con todos. Siempre acababan convirtiéndose en una algarabía, controlada al fin por algún "ya esta bien, niños" de su madre o una mirada seria de su padre.

Vio de nuevo, desde su cama de cuarterones blancos, como la luna entraba por las noches iluminando su habitación a través de la ventana abierta en el verano, y como mientras le pedía deseos se dormía soñando con caminos iluminados por estrellas.

Recordaba aquellos despertares bruscos y alborotados en la madrugada por la llegada de su tío Tito de América. ¡Eso sí que era un sueño real! me decía. Llegaba con unos baúles que abría de par en par ante la mirada de todos, desbordados y paralizados como por un encantamiento.

¡Que bien recordar todo aquello! Y siguió.... Se sintió como una pila cargándose. Se vio nítidamente, por fin, y se gustó tal como era. 


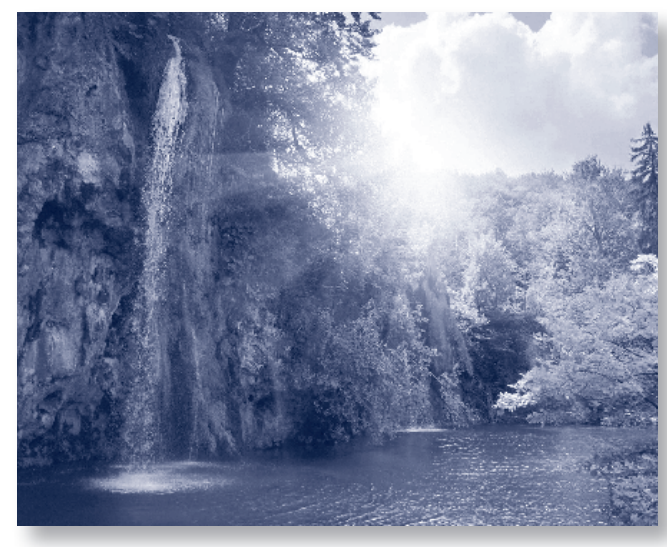

Se reconoció entonces con todo ese equipaje a su favor, con aquella maleta enorme y repleta. Podía abrirla y buscar cuando quisiera. No se había dado cuenta hasta ahora de su gran valor. Estaba llena a reventar pero no pesaba nada. Al revés, era la maleta la que tiraba de ella. Caminaba ilusionada, impulsada por ese depósito lleno de recuerdos, ilusiones y sueños.

Estábamos a finales verano. Se nos pasó la tarde volando entre tanto entusiasmo. Sentimos las dos en la cara la primera brisa fresca de Septiembre, esta vez llena de esperanza. No más de lo mismo de anteriores otoños, en que la cabeza se le llenaba de miedos. Para Juana, ahora todo era diferente.

Nos despedimos con la promesa de volver a vernos pronto de nuevo.

Durante este tiempo que ha pasado desde aquella tarde. Cuando pienso en Juana me traslado sin darme cuenta a una noche oscura en la que estoy mirando al cielo buscando alguna estrella.

Hace poco tiempo volví a verla y me contó como seguía sintiendo la vida cada día. Que no sabía como sería el futuro. Ella estaba en su ahora, en cada minuto. Me fije en sus ojos. Tenían un brillo especial.

Enseguida me trasladé a mi noche y miré al cielo pero esta vez estaba lleno de estrellas.
Estaba claro. Juana tenía y guardaba bien la llave, el secreto que trasforma una noche oscura en una noche estrellada.

En la esperanza de otra forma de vida prometedora de sueños y de estrellas... 